\title{
Electrophysiological correlates of state-dependent learning
}

\author{
HAROLD E. MODROW \\ Southern Illinois University, Carbondale, Illinois 62901 \\ and \\ DAVID K. BLISS \\ School of Medicine, Southern Illinois University, Carbondale, Illinois 62901
}

\begin{abstract}
Fourteen male Sprague-Dawley rats were implanted with recording electrodes in both the mesencephalic reticular formation (MRF) and the anterior polysensory cortex. After recovery, they were trained in a state-dependent learning paradigm utilizing a two-way shuttle avoidance procedure. We found that the animals trained under $15 \mathrm{mg} / \mathrm{kg}$ sodium pentobarbital learned the task faster than the saline-trained animals. Both recording sites showed a frequency difference between avoidance trials and error trials. Only the MRF showed a significant change in frequency at the onset of a trial. After criterion was reached, the animals were given overtraining trials. It was found that transfer to the opposite drug state was related positively to the amount of overtraining given. The MRF frequency in the test situation showed a difference between trials in which there was a response and those in which there was not. These results are discussed in relation to John's hypothesized circuits mediating the retrieval of memory.
\end{abstract}

The phenomenon of state-dependent learning has been the object of intense speculation and theoretical argument since Girden and Culler (1937) first addressed the problem. Although it has been found to occur in a wide variety of organisms, including goldfish, mice, rats, rabbits, cats, dogs, monkeys, and man (e.g., Bliss, 1973; Overton, 1964), the basic underlying mechanisms are still unknown.

Nearly all of the drugs which are capable of producing state-dependent learning have their primary site of action in the central nervous system (Bliss, 1974). A series of studies conducted by Overton $(1964,1968)$ indicated that the peripheral drug effects of some compounds do not significantly affect drug dissociation. Unfortunately, the number of studies investigating the central basis of state-dependent learning is limited. The first study to address this question was by Girden (1940). He found that bilateral ablation of the auditory cortex in dogs eliminated dissociation between a curare-induced drug state and the nondrug state. However, Bliss, Sledjeski, and Leiman (1971) demonstrated that a monkey with bilateral dorsolateral frontal ablation did dissociate between pentobarbital and saline. Girden (1943) also investigated the electro-

This research was supported in part by NIMH Grant MH27210 to D.K. Bliss and by the School of Medicine. Portions of this study were used as partial fulfillment of the requirements for the degree of Master of Arts at State University of New York at Binghamton by H.E. Modrow. Requests for reprints should be sent to D.K. Bliss, School of Medicine, Southern Illinois University, Carbondale, Illinois 62901. encephalogram (EEG) of dogs and monkeys under erythroidine. He found that animals' EEGs were within normal limits at dosages sufficient to produce drug dissociation. This suggests that EEG changes are not correlated with the central events producing dissociation. However, more recent studies have reported that changes in the EEG may be correlated with the dissociative effects of drugs. Sadowski and Longo (1962) found that the synchronization of the EEG after injection of scopolamine closely paralleled the disruption of a response learned under the nondrug state. Leiman, Bliss, Powers, and Rosenzweig (1967) showed that when rats were injected with pentobarbital at a dosage capable of producing dissociation, the EEG activity changed to high-amplitude synchronized waves from the normal arousal portrait of low-voltage desynchronized activity. This large change in electrical activity may well be correlated with the behavioral findings of drug dissociation.

Kletzkin and Swan (1959) hypothesized that drugs were able to produce a change in cortical EEG by acting on the reticular formation. This is because the reticular formation projects diffusely to, and profoundly affects neural activity in, many parts of the brain (French, Verzeano, \& Magoun, 1953). Majowski, Sobieszek, Kowalski, and Szwed (1970) found that avoidance conditioning took significantly longer in cats given mesencephalic reticular formation (MRF) lesions. It was hypothesized that the MRF might act as an inhibitory sensory transmission center. Thus, when a lesion was made in this area, extraneous sen- 
sory information might be able to reach the cortex.

Thompson (1967) has shown that the MRF has a major projection to specific regions of the cortex termed cortical association response areas or polysensory response areas. Buser, Borenstein, and Bruner (1959) investigated the visual, auditory, and somesthetic input to these areas in the cat, and found that they responded equally well to any of the three modalities of stimulation. Meikle (Note 1) investigated unit reponses to these three modalities in the rat association cortex and identified two polysensory areas, an anterior polysensory and a ventral posterior polysensory cortex. Gross evoked potentials from the polysensory areas differ from those of the primary sensory areas in having a longer latency and duration, and greater lability. The ability of polysensory evoked potentials to change over time suggests that they may be some portion of a neural network of memory consolidation.

John (1967) proposed that recall of a learned task was due to three neural circuits-the first one encoding the stimulus configuration present at the time of original learning; the second one encoding the exogenous and endogenous stimulus configuration at the time of recall; and the third neural circuit then comparing the firing patterns of the first two circuits to decide if the recall environment was similar to the original learning environment, in which case a response would be emitted. John proposed that the MRF was a part of the circuit which encodes the stimulus configuration at the time of original learning. We thought it possible that the polysensory cortex could be part of the stimulus circuit operative at the time of recall.

The purpose of the present study was to examine the electrophysiological changes taking place during learning and recall in a state-dependent paradigm. We investigated the possibility that the MRF and the polysensory cortex were related to the memory network proposed by John (1967) and that these areas were involved in the production of drug dissociation and transfer to the opposite drug state.

\section{METHODS}

\section{Subjects}

Fourteen adult naive male Sprague-Dawley rats weighing between 250 and $620 \mathrm{~g}$ at the beginning of the study were obtained from commercial breeders. Prior to and during the study, the animals were housed in individual wire cages and given ad-lib food and water.

\section{Surgery}

Five days prior to the start of training, each animal was anesthetized with pentobarbital for surgery. An insulated bipolar electrode was placed in the MRF. The coordinates, derived from König and Klippel (1963), were $4.4 \mathrm{~mm}$ posterior, $1.5 \mathrm{~mm}$ lateral, and $6.4 \mathrm{~mm}$ ventral to bregma. An additional monopolar electrode was placed on the surface of the anterior polysensory cortex $1.0 \mathrm{~mm}$ anterior and $1.0 \mathrm{~mm}$ lateral to bregma (Meikle, Note 1). This electrode was referenced to one of the three skull screws used to attach the electrode assembly to the skull.

\begin{abstract}
Apparatus
The apparatus consisted of a two-way shuttlebox measuring $46 \times 40 \times 20 \mathrm{~cm}$. The four sides and top were made of clear Plexiglas, while the floor was constructed of stainless steel bars through which footshock could be delivered. A light, flexible cable attached to the animal's electrode assembly led to a mercury commutator at the top of the apparatus. The commutator was connected to an electroencephalographic machine which printed out the animal's EEG.
\end{abstract}

\section{Procedure}

At the start of training, the animals were randomly assigned to either the drug or the nondrug training condition. The drugged animals were injected with $15 \mathrm{mg} / \mathrm{kg}$ sodium pentobarbital administered intraperitoneally $15 \mathrm{~min}$ prior to the start of training each day. The nondrug animals were injected with an equal volume of physiological saline $15 \mathrm{~min}$ prior to training. During the 15-min period, a cable was attached to the electrode assembly on the animal's head. After the animal was placed in the apparatus, the other end of the cable was attached to the commutator. The remainder of this $15-\mathrm{min}$ period was used to habituate the animal to the apparatus.

A $1,000-\mathrm{Hz}$ tone signaled the start of a trial. On training days, the animal had $10 \mathrm{sec}$ to avoid a $1.0-\mathrm{mA}$ shock by moving across the center of the apparatus. If the animal did not respond within the 10 -sec period, footshock was administered and remained on until the animal moved or an additional $10 \mathrm{sec}$ had elapsed, whichever occurred first. Training was given daily and consisted of 25 trials with a variable intertrial interval having a mean of $60 \mathrm{sec}$. Only training sessions were given until the animal had reached criterion (18 avoidances out of 20 consecutive trials on any 1 day). Following the day on which criterion was met, the animals were tested for five trials in the opposite drug state. Test parameters were the same as for training, except that footshock was not administered. Subsequent to this first test, the animals were given two 4-day overtraining blocks consisting of 75 trials (25/day) in the training state and 5 test trials in the opposite drug state. The EEG was recorded continuously on both the training and test days.

\section{Histology}

During the course of the study, four animals died of respiratory infections. Upon examination, their brains showed no gross damage, so their data are included in the analysis. All other animals were perfused and their brains examined at the conclusion of the study. Electrodes intended for placement in the MRF were in the proper location (shown in Figure 1A). The polysensory electrodes were also properly positioned (shown in Figure 1B).

\section{RESULTS}

Drug-trained animals learned the avoidance response significantly faster than did the saline-trained animals $[\mathrm{t}(12)=2.21, \mathrm{p}<.05]$. Drug-trained animals required a mean of 96.4 trials to reach criterion, while the saline-trained animals required a mean of 203.6 trials to reach the same criterion.

When the animals were tested in the opposite drug state the day after criterion was met, both groups of animals showed dissociation; that is, when animals were tested in the opposite drug state, they failed to recall the learned task. The mean number of responses during the five test trials was .71 for the drug-trained animals and .29 for the saline-trained animals. The difference between these two means was not significant. On the first day of overtraining (in the original learning state), all animals showed virtually perfect retention of the learned task, thus demonstrating state-dependent learning. 
(A)

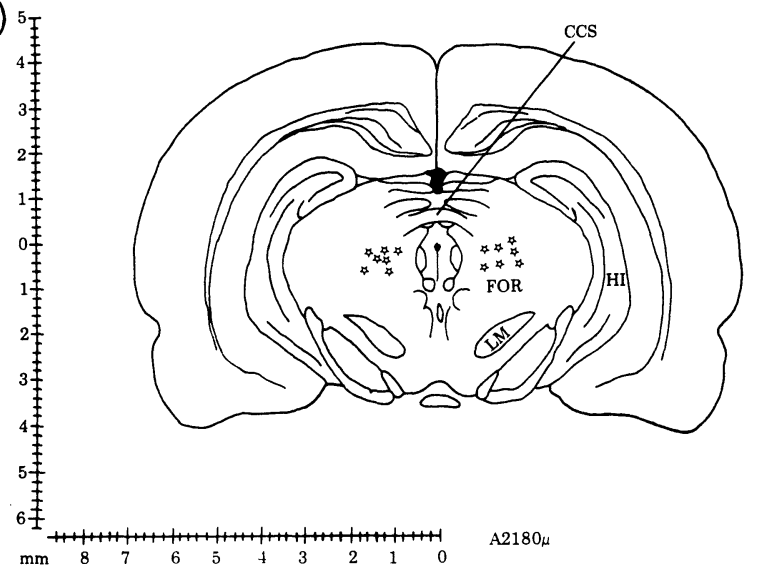

(B)

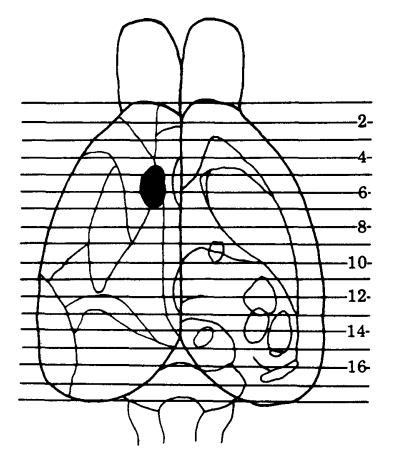

Figure 1. Diagrammatic representation of electrode locations. (A) Location of electrodes in the mesencephalic reticular formation. (B) Location of polysensory cortex electrode placements (shaded area).

We plotted the EEG frequencies manually. A total of 20 equally spaced trials prior to criterion were plotted for each animal. The 10 -sec period prior to each of these trials was also plotted. This method was used so that the learning curves would be more uniform. This meant using, for example, every 3rd trial for some animals and every 17 th trial for others. We found no difference in EEG frequency between the drug and the saline-trained groups in either of the two recording sites. Therefore, for the remainder of the analysis, the two training groups are pooled.

When we compared the EEG frequency before the trial to that during a trial, no change was found in the polysensory cortex. However, there was a significant change in the MRF frequency from before to during a trial $[\mathrm{F}(1,11)=5.2, \mathrm{p}<.05]$. The mean frequency before a trial was $5.9 \mathrm{~Hz}$, while during a trial it increased to $6.1 \mathrm{~Hz}$.

There was also a significant difference in frequency between errors and avoidances for both recording sites. The mean frequency of the MRF on error trials was $5.8 \mathrm{~Hz}$, while for avoidance trials the mean frequency was $6.2 \mathrm{~Hz}$. This difference is statistically significant $[F(1,11)=17.8, p<.01]$. A similar significant difference was found in the polysensory cortex
$[\mathrm{F}(1,11)=24.2, \mathrm{p}<.001]$, where the mean frequency on error trials was $5.7 \mathrm{~Hz}$, while on avoidance trials it was $6.2 \mathrm{~Hz}$.

The amount of transfer shown during successive test sessions was a function of the amount of overtraining that had occurred. Drug-trained and saline-trained animals did not significantly differ with regard to the amount of transfer evident during testing in the opposite state. Thus, their data are shown together in Figure 2. The overall positive slope of the performance curve supports the idea that overtraining is positively related to the amount of transfer shown (Bliss, 1974).

We found no difference in the polysensory EEG frequencies between the test trials in which a response was shown and those in which there was no response. The MRF did, however, show a significant difference in frequency $[\mathrm{F}(1,11)=6.6, \mathrm{p}<.05]$ between the two types of trials during testing in the opposite drug state. This is shown in Figure 3. As may be seen in this figure, the difference in frequency is in the same direction as that shown between avoidances and errors in the training state.

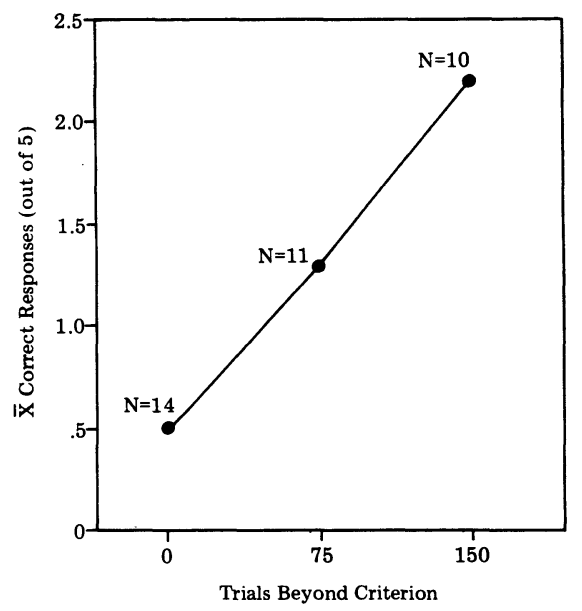

Figure 2. Relationship of the degree of overtraining to the amount of transfer shown during tests in the opposite state.

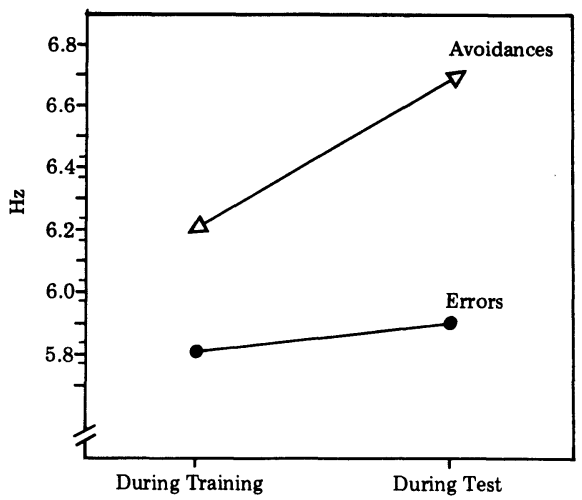

Figure 3. Mesencephalic reticular formation mean EEG frequencies during training and testing in the opposite drug state. Mean frequencies are shown separately for avoidance and error trials. 


\section{DISCUSSION}

Other studies in our laboratory have found that drug and saline-trained rats will learn this avoidance response equally rapidly (Modrow, Skala, Petroff, \& Bliss, 1978). The slower learning of the saline-trained rats here might indicate that even though they did reach criterion, the task was not as well learned as in the case of the drug-trained rats. However, this does not appear to be the case, because during overtraining the performance of the saline-trained animals was equivalent to that of the drug-trained animals.

Iwahara and Noguchi (1972) examined the effect of overtraining on transfer to the opposite drug state. They found that overtraining in the drug state did lead to increased transfer to the nondrug state. They did not, however, look at overtraining, and the resultant transfer from the nondrug to the drug condition, as we have done here.

One surprising result was the lack of a difference between the EEG's of the drug-trained and the salinetrained animals in the MRF. Kletzkin and Swan (1959) did find such a difference. One possible explanation for this discrepancy may be the use of different drug dosages. Another may be that because the MRF is a large and diffuse area, recording from different sites may result in different findings.

The lack of difference in polysensory cortical EEG frequency before a trial and during a trial may indicate that this area is not involved in John's (1967) hypothesized circuit encoding the current external and internal stimulus environment. If it were a part of this hypothesized circuit, we would expect a change to occur at the tone onset, signaling a trial. This was not the case, at least that we could detect using our methods.

However, the pattern of changes seen in the MRF does support its role in a circuit mediating memory. The MRF EEG frequency was found to show a change at the onset of a trial. This could indicate that the MRF is actively involved in a circuit encoding the stimulus environment at the time of learning. There was also a difference found between trials in which the animal avoided and those in which an error occurred. The results obtained in the opposite testing state also tend to support the hypothesis that the MRF is involved in the encoding of memory for the task. The EEG of the MRF was significantly different when a response was made as compared to when there was no response. This might indicate that when the animal perceived a situation similar to the learning situation, as measured by the EEG, he responded. When the situation was dissimilar, as measured by the EEG, no response was made. It is at least possible that the MRF is a major element in the production of state-dependent learning. By incorporating both the external and the internal stimulus environments found during learning, the organism separates the behaviors produced under dissimilar drug states into separate circuits allowing for drug dissociation.

\section{REFERENCE NOTE}

1. Meikle, M. Unit response in rat association cortex in response to auditory, visual and tactile stimuli. Paper presented at the meeting of the Western Psychological Association, San Diego, 1968.

\section{REFERENCES}

BuIss, D. K. Dissociated learning and state dependent retention in the rhesus monkey. Journal of Comparative and Physiological Psychology, 1973, 84, 149-161.

BuIss, D. K. Theoretical explanations of drug dissociated behavior. Federation Proceedings, 1974, 33, 1787-1796.

Bliss, D. K., Sledjeski, M., \& Leiman, A. L. State-dependent choice behavior in the rhesus monkey. Neuropsychologia, 1971, 9, 51-59.

Buser, P., Borenstein, P., \& Bruner, J. Étude dès systèmes "associatifs" visuèls et auditifs chez le chat anesthesie au chloralose. Electroencephalography and Clinical Neurophysiology, 1959, 11, 305-324.

French, J. D., Verzeano, J., \& Magoun, H. W. An extralemniscal sensory system in the brain. Archives of Neurological Psychiatry, 1953, 69, 505-518.

GIRDEN, E. Cerebral mechanisms in conditioning under curare. American Journal of Psychology, 1940, 53, 397-406.

GIRDEN, E. Effect of striated muscle paralysis induced with enthroidine upon electroencephalogram (EEG). Proceedings of the Society of Experimental Biology and Medicine, 1943, 53, 163-164.

Girden, E., \& Culler, E. Cerebral mechanisms in conditioning under curare. Journal of Comparative Psychology, 1937, 23, 261-274.

IWAHARA, S., \& Noguchi, S. Drug state dependency as a function of overtraining in rats. Japanese Psychological Research, 1972, 14, 141-144.

John, E. R. Mechanisms of memory. New York: Academic Press, 1967.

KLETZKin, M., \& Swan, K. The effects of meprobamate and pentobarbital upon cortical and subcortical responses to auditory stimulation. Journal of Pharmacology and Experimental Therapeutics, 1959, 125, 35-39.

Konig, J. F. R., \& KLIPPEL, R. A. The rat brain. Baltimore: Williams \& Wilkins, 1963.

Leiman, A. L., Bliss, D. K., Powers, J., \& Rosenzweig, M. R. Electrophysiological correlates of drug dissociation. Federation Proceedings, 1967, 26, 363. (Abstract)

Majkowski, J., Sobieszek, A., Kowalski, M., \& Szwed, M. EEG and behavioral correlates in cats with lesions in the mesencephalic reticular formation. Brain Research, 1970, 21, 301-304.

Modrow, H. E., Skala, K. D., Petroff, R., \& Bliss, D. K. Physiological substrates of state dependent learning. In F. C. Colpaert and J. A. Rosecrans (Eds.), Stimulus properties of drugs: Ten years of progress. Amsterdam: Elsevier, 1978.

Overton, D. A. State dependent or "dissociated" learning produced with pentobarbital. Journal of Comparative and Physiological Psychology, 1964, 57, 3-12.

Overton, D. A. Visual cues and shock sensitivity in the control of T-maze choice by drug conditions. Journal of Comparative and Physiological Psychology, 1968, 66, 216-219.

SADowsKi, B., \& Longo, V. G. EEG and behavioral correlates of an instrumental reward conditioned response in rabbits: A physiological and pharmacological study. Electroencephaloggraphy and Clinical Neurophysiology, 1962, 14, 465-476.

Thompson, R. F. Foundations of physiological psychology. New York: Harper \& Row, 1967.

(Received for publication November 17, 1978; revision accepted February 5, 1979.) 